\title{
A Plasminogen Activator Inhibitor-1 Promoter Polymorphism and Idiopathic Interstitial Pneumonia
}

\author{
KeVin K Kim, ${ }^{1}{ }^{\text {KeVin R. Flaherty, }}{ }^{1}$ Qi Long $^{2}{ }^{2}$ Noboru Hattori, ${ }^{1}$ ThOMAS H. Sisson, $^{1}$ \\ Thomas V Colby, ${ }^{3}$ William D Travis, ${ }^{4}$ Fernando J Martinez, ${ }^{1}$ Susan Murray, ${ }^{2}$ \\ AND RICHARD H SIMON ${ }^{1}$
}

The normal fibrinolytic activity within the alveolar space is suppressed in fibrotic lung diseases in part because of increased levels of plasminogen activator inhibitor-1 (PAI-1). Studies with animals have shown that inhibition of the plasminogen system by PAI- 1 increases the generation of pulmonary fibrosis. To determine if a similar relationship occurs in human fibrotic lung diseases, we took advantage of a polymorphism $(4 \mathrm{G} / 5 \mathrm{G})$ that occurs in the promoter region of the human PAl-1 gene and influences the expression of PAl-1. We hypothesized that the 4G/4G genotype, because of its association with higher levels of PAl-1, would occur in patients with idiopathic interstitial pneumonia more frequently than in a control population. PAI-1 promoter genotype was determined in 88 well-characterized patients with idiopathic interstitial pneumonia consisting of 62 patients with usual interstitial pneumonia and 26 with nonspecific interstitial pneumonia. DNA was extracted from paraffinembedded biopsy tissue and the genotype identified by polymerase chain reaction and restriction endonuclease digestion. We found that the distribution of PAl-1 genotypes in the idiopathic interstitial pneumonia population was similar to that of a large control population. However, subgroup analysis showed that patients with nonspecific interstitial pneumonia were more likely than the control population to have the promoter genotype $(4 \mathrm{G} / 4 \mathrm{G})$ that is associated with higher levels of PAl-1. A similar pattern in PAI-1 polymorphism was not seen in the usual interstitial pneumonia subgroup. The results of this study support the conclusion that PAl-1 expression influences the development of nonspecific interstitial pneumonia in a similar manner to what occurs in animal models of pulmonary fibrosis. Patients with usual interstitial pneumonia did not show the same relationship with PAI-1 genotype.

\section{INTRODUCTION}

Fibrin accumulation is a common feature in many acute and chronic lung diseases. Damage to the alveolar walls causes extravasation of plasma proteins into the interstitium and alveolar spaces where increased levels of tissue factor lead to the accumulation of fibrin and other matrix components $(1,2)$. The fate of this provisional matrix likely is an important determinant of whether the alveolar structures are successfully repaired or are replaced by collagenous scars. In a normal lung, urokinase-type plasminogen activator is produced by pulmonary epithelial cells $(3,4)$ and alveolar macrophages (5), thereby generating a net fibrinolytic environment in the alveolar space. However, in patients with fibrotic lung diseases, fibrin deposits persist because the normal fibrinolytic activity is suppressed by increases in proteolytic inhibitors such as plasminogen activator inhibitor-1 (PAI-1) (6,7).

Manipulation of PAI-1 levels in animal models of lung injury influences the degree of fibrosis that occurs. Mice with deletion of both copies of their PAI-1 gene are relatively protected from bleomycin-induced pulmonary fibrosis, while mice that are heterozygous for the PAI-1 deletion have an intermediate level of susceptibility compared with wild-type mice (8). Furthermore, transgenic mice that overexpress PAI-1 develop more pulmonary fibrosis following bleomycin injury. Thus, there is a direct correlation between the genetically determined level of PAI-1 expression and the extent of collagen accumulation that follows lung injury.

To determine if variations in PAI-1 expression can influence pulmonary fibrosis in humans, we took advantage of a polymorphism in the human PAI-1 gene. An insertion or deletion of a single guanine in the upstream promoter yields alleles containing either 4 or 5 consecutive guanines (4G or 5G) (9). Individuals in the general population who are homozygous $4 \mathrm{G} / 4 \mathrm{G}$ have an $18 \%$ higher plasma level of PAI-1 compared with the group with either the $4 \mathrm{G} / 5 \mathrm{G}$ or $5 \mathrm{G} / 5 \mathrm{G}$ genotype (10). Furthermore, in vitro studies using the Hep2G cell line have shown that following stimulation with interleukin-1, the 4G PAI-1 promoter, is 6-fold more active than the $5 \mathrm{G}$ promoter (9).

Clinical studies have evaluated the role of the PAI-1 polymorphism in several diseases where fibrin deposition and fibrinolysis may be important. Recent meta-analyses have shown a statistically significant increase in risk of myocardial infarction in individuals with the $4 \mathrm{G} / 4 \mathrm{G}$ genotype $(11,12)$. The $4 \mathrm{G} / 4 \mathrm{G}$ genotype also has been associated with asthma, allergy $(13,14)$, shock from meningococcal sepsis $(15,16)$, death following trauma (17),

'Division of Pulmonary and Critical Care Medicine, Department of Internal Medicine, University of Michigan School of Medicine, Ann Arbor, Ml; ${ }^{2}$ Department of Biostatistics, University of Michigan School of Public Health, Ann Arbor, MI; ${ }^{3}$ Department of Pathology, Mayo Clinic, Scottsdale, Az; ${ }^{4}$ Department of Pulmonary and Mediastinal Pathology, Armed Forces Institute of Pathology, Washington DC. 
and the development of macroangiopathy (18) and nephropathy (19) in diabetes.

In the present study, we investigated the influence of the PAI-1 polymorphism in patients with idiopathic interstitial pneumonia (IIP). We hypothesized that the $4 \mathrm{G} / 4 \mathrm{G}$ genotype, because of its association with increased levels of PAI-1, will be found in more patients with IIP than in the control group. For purposes of this study, we limited the analyses to a subset of IIP patients having usual interstitial pneumonia (UIP) or nonspecific interstitial pneumonia (NSIP) to generate a more uniform population for study.

\section{MATERIALS AND METHODS}

\section{Study Population}

The study used patients from the University of Michigan Specialized Center of Research in the Pathobiology of Fibrotic Lung Disease database. Patients used for the study were required to have a surgical lung biopsy, a pathological diagnosis of UIP or NSIP as interpreted by 2 pulmonary pathologists, and the availability of paraffin-embedded tissue samples from the clinical pathology laboratory at the University of Michigan. Patients with known collagen vascular disease or drug reactions were excluded. The histological criteria that were used for UIP and NSIP were the same as previously published (20). All specimens were reviewed to confirm diagnostic consistency. Genetic and clinical data were coded and stored anonymously. All aspects of the study were reviewed and approved by the University of Michigan Institutional Review Board for human subject research.

\section{Genotyping}

DNA was extracted from $25-\mu$ m-thick sections of formalin-fixed, paraffin-embedded tissue obtained from surgical biopsy or autopsy. Each section was mixed with $400 \mu \mathrm{L}$ xylene and incubated for $5 \mathrm{~min}$ at $21{ }^{\circ} \mathrm{C}$. The sample was centrifuged at $14000 \mathrm{rpm}$ for $5 \mathrm{~min}$, and the pellet was resuspended in $400 \mu \mathrm{L}$ xylene. After the mixture was incubated at $21{ }^{\circ} \mathrm{C}$ for $5 \mathrm{~min}, 400 \mu \mathrm{L} 100 \%$ ethanol was added and incubated for another $5 \mathrm{~min}$. Following centrifugation at $14000 \mathrm{rpm}$ for $5 \mathrm{~min}$, the pellet was resuspended in $1 \mathrm{~mL}$ of $50 \mathrm{mM}$ Tris $\mathrm{HCl}, 1 \mathrm{mM}$ EDTA, 0.5\% TWEEN 20, $\mathrm{pH}$ 8.5. The sample then was digested by adding $10 \mu \mathrm{L}$ proteinase $\mathrm{K}$ (> $20 \mathrm{U} / \mathrm{mg}, 10 \mathrm{mg} / \mathrm{mL}$ ) and incubating overnight at $37{ }^{\circ} \mathrm{C}$. Proteinase $\mathrm{K}$ was inactivated by heating the sample to $95{ }^{\circ} \mathrm{C}$ for $7 \mathrm{~min}$. The sample was centrifuged at $14000 \mathrm{rpm}$ for $5 \mathrm{~min}$, and the supernatant was stored at $-20^{\circ} \mathrm{C}$ until genetic analysis.

PAI-1 promoter genotype then was determined as previously described (21). Briefly, the relevant region of the PAI-1 promoter was amplified by polymerase chain reaction using a mutated upstream primer that inserts a BslI restriction site in the $5 \mathrm{G}$ allele but not the $4 \mathrm{G}$ allele. Following BslI digestion the $5 \mathrm{G}$ allele yields a 77-bp and 22-bp product whereas the $4 \mathrm{G}$ allele remains undigested at $98 \mathrm{bp}$. The digestion products were fractionated by $3 \%$ agarose gel electrophoresis in $0.04 \mathrm{M}$ Tris-acetate, $1 \mathrm{mM} \mathrm{Na}_{2}$ EDTA, pH 8.3.

\section{Statistical Analysis}

Two sample $t$ tests were used for 2 group comparisons of continuous variables, and chi-square tests were used to compare geno-
Table 1. Characteristics of 88 patients with IIP grouped by PAI-1 genotype

\begin{tabular}{|c|c|c|c|}
\hline & $4 G / 4 G$ & $\begin{array}{l}4 G / 5 G \\
5 G / 5 G\end{array}$ & $P$ value \\
\hline Female/Male & $12 / 13$ & $29 / 34$ & 0.867 \\
\hline History of smoking ${ }^{a}$ (Yes/No) & $17 / 7$ & $36 / 22$ & 0.450 \\
\hline $\begin{array}{l}\text { Cigarette consumption for smokers, } \\
\text { pack-years }^{b}\end{array}$ & $32.2 \pm 5.1$ & $30.2 \pm 3.7$ & 0.762 \\
\hline Age at surgical lung biopsyb & $54.8 \pm 2.2$ & $61.8 \pm 1.2$ & 0.003 \\
\hline $\begin{array}{l}\text { Years with symptoms prior to surgical } \\
\text { lung biopsyb }\end{array}$ & $3.0 \pm 0.7$ & $2.4 \pm 0.4$ & 0.448 \\
\hline
\end{tabular}

asmoking history not available on 6 patients.

${ }^{b}$ Mean \pm SEM.

type distributions and to evaluate differences between genotype groups on categorical variables (SAS Institute, Cary, NC, USA). A value of $P<0.05$ was considered statistically significant. The DSTPLAN package was used for power calculations (22).

\section{RESULTS}

\section{Study Population}

Eighty-eight patients with IIP were used in the study. Their demographic and clinical characteristics at the time of surgical lung biopsy are presented according to genotype in Table 1 . The distribution of patient gender was similar between the $4 \mathrm{G} / 4 \mathrm{G}$ and the combined $4 \mathrm{G} / 5 \mathrm{G}$ and $5 \mathrm{G} / 5 \mathrm{G}$ groups. A majority of the patients were current or former smokers. The average age of the IIP patients was similar to the previously reported age distribution of IIP patients (23). However, the patients in the $4 \mathrm{G} / 4 \mathrm{G}$ group were significantly younger at the time of surgical lung biopsy than the age of patients with other genotypes. The duration of symptoms prior to surgical lung biopsy was similar in both groups.

PAI-1 Genotype and Allele Frequency of Patients with IIP The genotype and allele frequencies of patients with IIP are presented in Figure 1 where they are compared with those of a control population consisting of 2120 subjects whose genotypes were reported as part of a meta-analysis of PAI-1 polymorphisms in coronary artery disease (11). The proportion of $4 \mathrm{G} / 4 \mathrm{G}$ relative to combined 4G/5G and 5G/5G genotypes did not differ between the IIP and control groups $(P=0.92)$. Likewise, there was no significant difference in the distribution of $4 \mathrm{G}$ and $5 \mathrm{G}$ alleles between IIP and control groups $(P=0.30)$. Further exploratory analysis of the data led us to evaluate the relationship between pathological diagnosis (UIP or NSIP) and the PAI-1 polymorphism. The prominent finding was the overrepresentation of the $4 \mathrm{G} / 4 \mathrm{G}$ relative to combined $4 \mathrm{G} / 5 \mathrm{G}$ and $5 \mathrm{G} / 5 \mathrm{G}$ genotypes in the NSIP subgroup compared with the control population (Figure 2A, $P=0.05)$. This relationship also was reflected in a higher proportion of $4 \mathrm{G}$ relative to $5 \mathrm{G}$ alleles in the NSIP group (see Figure $2 \mathrm{~B}$, $P=0.04)$. In contrast, when similar analyses were performed comparing the UIP and control groups, no differences in the distribution of genotype frequencies $(P=0.17)$ or allele frequencies $(P=0.92)$ were seen. The differences in genotype and allele distributions also were apparent when the NSIP and UIP groups were 


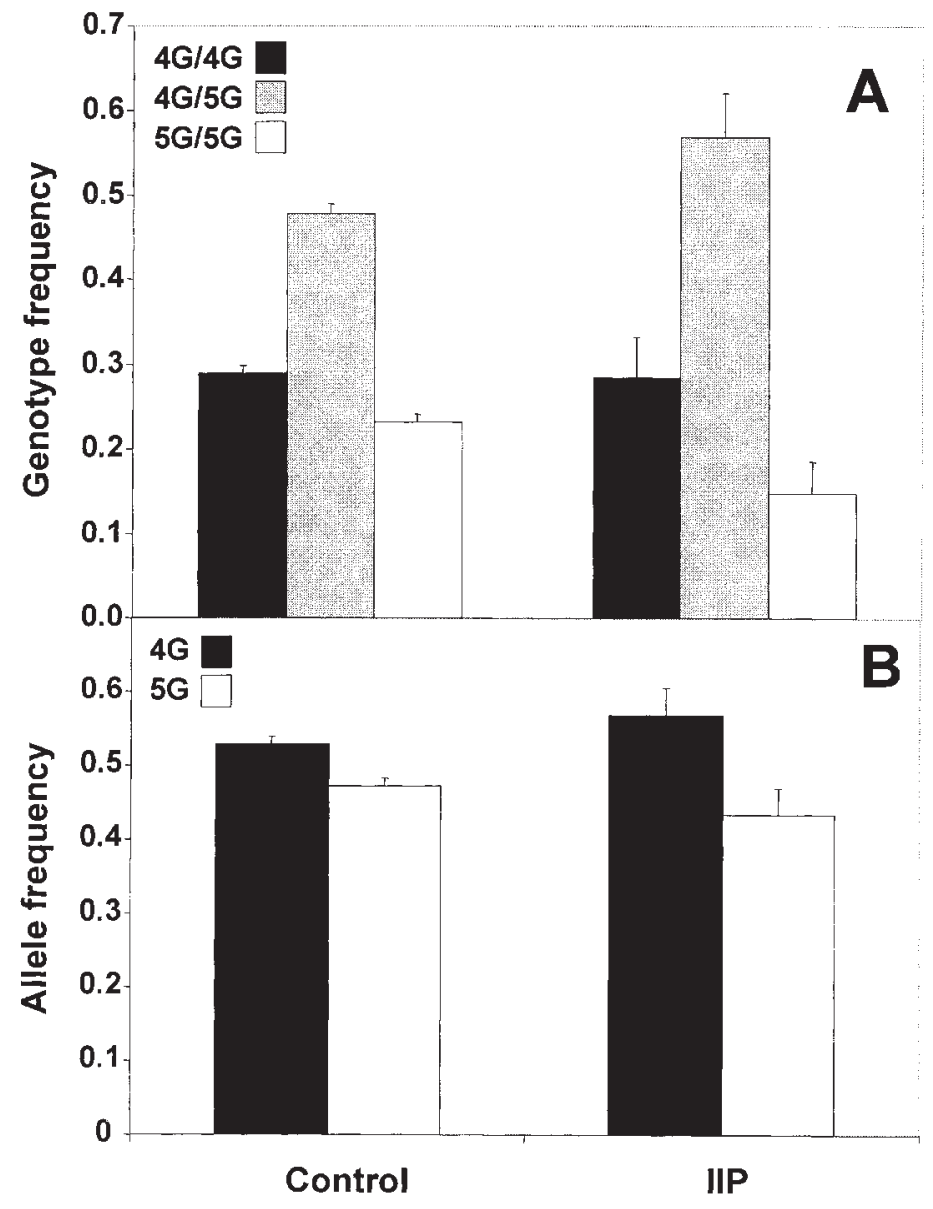

Figure 1. PAI-1 promoter polymorphism distribution of patients with IIP compared with that of a control population. A: Genotype frequencies. The distribution of $4 \mathrm{G} / 4 \mathrm{G}$ relative to combined $4 \mathrm{G} / 5 \mathrm{G}$ and $5 \mathrm{G} / 5 \mathrm{G}$ did not differ between IIP and control groups $(P=0.92)$. B: Allele frequencies. The frequency of $4 \mathrm{G}$ relative to $5 \mathrm{G}$ did not differ between IIP and control groups $(P=0.30)$. Bars, mean + SEM.

compared. The frequency of the $4 \mathrm{G} / 4 \mathrm{G}$ genotype relative to the combined $4 \mathrm{G} / 5 \mathrm{G}$ and 5G/5G genotypes was higher in the NSIP group than the UIP group $(P=0.02)$, and there was a trend toward a higher frequency of the $4 \mathrm{G}$ allele in the NSIP group compared with the UIP group $(P=0.057)$.

\section{DISCUSSION}

The large control population of 2120 subjects that was used for the genetic comparisons was obtained from a meta-analysis of 9 published studies evaluating risk factors for coronary artery disease (11). This and other studies have shown that the distribution of PAI-1 genotype is very similar across ethnic groups. For example, the frequencies of the $4 \mathrm{G}$ allele in the control populations that were reported in 4 of the larger published studies performed in Germany (24), the United States (25), Western Europe (26), and the Czech Republic (14) were 0.54, 0.52, 0.54, and 0.51, respectively. Because of the uniformity of allele frequencies in these populations, we were able to use these data reliably for our analyses.

Although our results did not demonstrate an effect of PAI-1 genotype when the entire IIP population was examined, explorato- ry analyses showed important differences when the UIP and NSIP patients were considered separately. Specifically, the distribution of the $4 \mathrm{G} / 4 \mathrm{G}$ genotype and the $4 \mathrm{G}$ allele within the NSIP subgroup was significantly higher than in the control population. A similar trend was not seen in the UIP population where the frequencies were not different from that of the control population. The differential effect of genotype on UIP and NSIP also was apparent when the 2 histological groups were compared. In particular, the relative frequency of the $4 \mathrm{G} / 4 \mathrm{G}$ genotype was significantly higher in NSIP compared with UIP. Thus, the results showing a difference between UIP and NSIP are consistent whether comparisons are made using data from the large published control population or using data from this study.

The observation that patients with the $4 \mathrm{G} / 4 \mathrm{G}$ allele were younger than those in the combined $4 \mathrm{G} / 5 \mathrm{G}$ and $5 \mathrm{G} / 5 \mathrm{G}$ group (see Table 1 ) is a consequence of having NSIP overrepresented relative to UIP within the $4 \mathrm{G} / 4 \mathrm{G}$ group. Patients with NSIP have been reported to be younger at the time of diagnosis than UIP patients (27).

Alternative experimental approaches are being used to study genetic influences on human diseases. For example, microarray

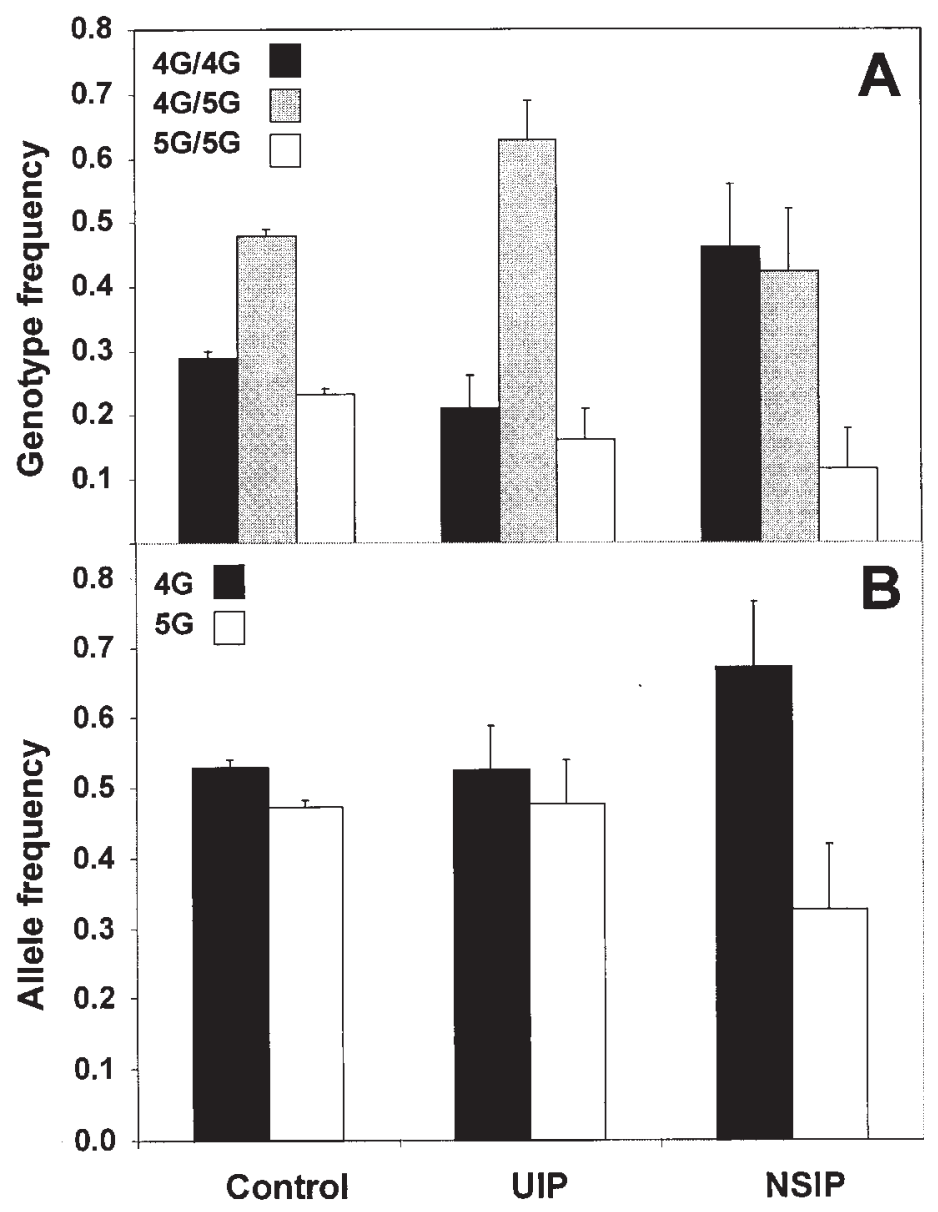

Figure 2. PAl-1 promoter polymorphism distribution within histological subtypes of idiopathic interstitial pneumonia. A: Genotype frequencies. When compared with the control population, the frequency of $4 \mathrm{G} / 4 \mathrm{G}$ relative to combined $4 \mathrm{G} / 5 \mathrm{G}$ and $5 \mathrm{G} / 5 \mathrm{G}$ was higher in the NSIP group $(P=0.05)$, but not in the UIP group $(P=0.17)$. B: Allele frequencies. When compared with the control population, the frequency of $4 \mathrm{G}$ relative to $5 \mathrm{G}$ was higher in the NSIP group $(P=0.04)$, but not the UIP group $(P=0.92)$. Bars, mean + SEM. 
technology is being employed to search for disease susceptibility genes by simultaneously determining the genotype at a very large number of polymorphic loci in patients having a particular disease. Statistical analyses of these exploratory studies must take into account the large number of comparisons that are being made in identifying genuine signal from statistical noise. In many circumstances, subsequent studies are needed to validate the observed genotype-phenotype relationships and to understand how the particular gene can influence the disease process. In some cases, the polymorphic gene is merely in linkage disequilibrium with the true disease susceptibility gene and has no contributory role to the pathogenesis. Contrary to this experimental strategy, the current study is hypothesis-driven and is based upon a detailed understanding of the molecular biology of PAI-1 and how it influences the development of fibrotic lung disease in animal models. This large quantity of scientific evidence directly led to our concise hypothesis that human fibrotic lung disease is influenced by a specific genetic variation that affects the level of PAI-1 expression in humans. The precise nature of our hypothesis reduces the problems that would otherwise occur if we were performing large numbers of exploratory comparisons with the subsequent burden of determining their biological relevance. Although the current study did involve more than one statistical analysis, we believe that the observed association between the PAI-1 polymorphism and NSIP likely is genuine based upon the limited number of analyses performed and the strong supporting biological evidence obtained from in vitro and animal studies.

Although our study size was sufficient to detect a statistically significant effect of PAI-1 genotype on NSIP, the power of the study was not high enough to exclude a more subtle effect of PAI-1 genotype on UIP and hence on the combined IIP group. For example, the true frequency of the $4 \mathrm{G} / 4 \mathrm{G}$ genotype in a sample of 62 UIP patients would have to be 15 percentage points higher than the observed $28.9 \%$ level of the control population to be detectable at the $5 \%$ significance level with $80 \%$ power. A lesser but present effect of the PAI-1 polymorphism may not be reliably detected using the number of patients with UIP that were available to our study.

There continues to be considerable debate whether UIP and NSIP are different manifestations of the same disease or are distinct entities (28-30). The pathological characteristics of UIP include the destruction of alveolar architecture in a patchy distribution with different areas of lung having variable proportions of fibroblastic foci and collagenous scars (27). The features of NSIP are more uniform within a single patient and consist of interstitial inflammation and/or fibrosis with relative preservation of alveolar architecture. While our study does not resolve the debate as to the relationship of UIP and NSIP, we have demonstrated several differences between them. We have shown an effect of PAI-1 promoter polymorphism on patients with NSIP but not on patients with UIP. Furthermore, our patients with NSIP presented at a younger age correlating well with previous studies $(29,31)$. This latter observation is unlikely to be an artifact due to a lead-time bias because the average time between the onset of symptoms and lung biopsy in our study did not differ between UIP and NSIP patients. These findings would suggest that UIP and NSIP are distinct entities. It must be acknowledged that some patients with IIP have histological features of both UIP and NSIP in different lobes of their lungs (28). Whether PAI-1 genotype influences clinical features in this overlap group will require further studies that include substantial numbers of these patients.

In conclusion, we have demonstrated a relationship between a PAI-1 promoter polymorphism and the development of NSIP. This relationship is similar to what has been demonstrated in animal models where increased levels of PAI-1 are associated with worse pulmonary fibrosis. A similar relationship between this PAI-1 polymorphism and UIP was not apparent from our study.

\section{ACKNOWLEDGMENTS}

This work was supported by National Institutes of Health Grants K08 HL04434, K23 HL68713, K24 HL04212, P50 HL56402. Dr Kathleen A Cooney provided advice concerning the PAI-1 promoter genotyping.

Address correspondence and reprint requests to Richard $\mathrm{H}$. Simon, 6301 MSRB-3, Box 0642, 1150 W. Medical Center Drive, University of Michigan Health Sciences Center, Ann Arbor, Ml 48109-0642. Phone: 734-764-4554, fax: 734-764-4556, e-mail: richsimo@umich.edu.

Submitted November 25, 2002; accepted for publication on December 24, 2002.

\section{REFERENCES}

1. Katzenstein AL. (1985) Pathogenesis of "fibrosis" in interstitial pneumonia: an electron microscopic study. Hum. Pathol. 16:1015-24.

2. Kuhn $\mathrm{C}$ et al. (1989) An immunohistochemical study of architectural remodeling and connective tissue synthesis in pulmonary fibrosis. Am. Rev. Respir. Dis. 140:1693-703.

3. Marshall BC, Sageser DS, Rao NV, Emi M, Hoidal JR. (1990) Alveolar epithelial cell plasminogen activator. Characterization and regulation. J. Biol. Chem. 265: 8198-204.

4. Gross TJ, Simon RH, Kelly CJ, Sitrin RG. (1991) Rat alveolar epithelial cells concomitantly express plasminogen activator inhibitor-1 and urokinase. Am. J. Physiol. 260:L286-95.

5. Chapman Jr HA, Stone OL, Vavrin Z. (1984) Degradation of fibrin and elastin by intact human alveolar macrophages in vitro. Characterization of a plasminogen activator and its role in matrix degradation. J. Clin. Invest. 73:806-15.

6. Chapman HA, Allen CL, Stone OL. (1986) Abnormalities in pathways of alveolar fibrin turnover among patients with interstitial lung disease. Am. Rev. Respir. Dis. 133:437-43.

7. Gunther A et al. (2000) Enhanced tissue factor pathway activity and fibrin turnover in the alveolar compartment of patients with interstitial lung disease. Thromb. Haemost. 83:853-60.

8. Eitzman DT et al. (1996) Bleomycin-induced pulmonary fibrosis in transgenic mice that either lack or overexpress the murine plasminogen activator inhibitor-1 gene. J. Clin. Invest. 97:232-7.

9. Dawson SJ et al. (1993) The two allele sequences of a common polymorphism in the promoter of the plasminogen activator inhibitor-1 (PAl-1) gene respond differently to interleukin-1 in HepG2 cells. J. Biol. Chem. 268:10739-45.

10. Margaglione M et al. (1998) PAI-1 plasma levels in a general population without clinical evidence of atherosclerosis: relation to environmental and genetic determinants. Arterioscler. Thromb. Vasc. Biol. 18:562-7.

11. Iacoviello L et al. (1998) The 4G/5G polymorphism of PAl-1 promoter gene and the risk of myocardial infarction: a meta-analysis. Thromb. Haemost. 80:1029-30.

12. Boekholdt SM et al. (2001) Genetic variation in coagulation and fibrinolytic proteins and their relation with acute myocardial infarction: a systematic review. Circulation 104:3063-68.

13. Cho SH et al. (2001) Possible role of the $4 \mathrm{G} / 5 \mathrm{G}$ polymorphism of the plasminogen activator inhibitor 1 gene in the development of asthma. J. Allergy Clin. Immunol. 108:212-4.

14. Buckova D, Izakovicova Holla L, Vacha J. (2002) Polymorphism 4G/5G in the plasminogen activator inhibitor-1 (PAI-1) gene is associated with IgE-mediated allergic diseases and asthma in the Czech population. Allergy 57:446-8.

15. Hermans PW et al. (1999) 4G/5G promoter polymorphism in the plasminogenactivator-inhibitor-1 gene and outcome of meningococcal disease. Meningococcal Research Group. Lancet 354:556-60.

16. Westendorp RG, Hottenga JJ, Slagboom PE. (1999) Variation in plasminogenactivator-inhibitor-1 gene and risk of meningococcal septic shock. Lancet 354 561-63. 
17. Menges T et al. (2001) Plasminogen-activator-inhibitor-1 4G/5G promoter polymorphism and prognosis of severely injured patients. Lancet 357:1096-7.

18. Kimura $\mathrm{H}$ et al. (1998) Polymorphisms of angiotensin converting enzyme and plasminogen activator inhibitor-1 genes in diabetes and macroangiopathyl. Kidney Int. 54:1659-69.

19. Wong TY, Poon P, Szeto CC, Chan JC, Li PK. (2000) Association of plasminogen activator inhibitor-1 4G/4G genotype and type 2 diabetic nephropathy in Chinese patients. Kidney Int. 57:632-8.

20. Flaherty KR et al. (2002) Clinical significance of histological classification of idiopathic interstitial pneumonia. Eur. Respir. J. 19:275-83.

21. Margaglione $M$ et al. (1997) An alternative method for PAl-1 promoter polymorphism (4G/5G) typing. Thromb. Haemost. 77:605-6.

22. Brown BW et al. (2000) DSTPLAN [computer program]. Version 4.2. Houston, (TX) University of Texas, M.D. Anderson Cancer Center, Department of Biomathematics.

23. Anonymous. (2000) Idiopathic pulmonary fibrosis: diagnosis and treatment. Am. J. Respir. Crit. Care Med. 161:646-64.

24. Gardemann A et al. (1999) The 4G4G genotype of the plasminogen activator inhibitor $4 G / 5 G$ gene polymorphism is associated with coronary atherosclerosis in patients at high risk for this disease. Thromb. Haemost. 82:1121-6.

25. Ridker PM, Hennekens CH, Lindpaintner K, Stampfer MJ, Miletich JP. (1997)
Arterial and venous thrombosis is not associated with the $4 \mathrm{G} / 5 \mathrm{G}$ polymorphism in the promoter of the plasminogen activator inhibitor gene in a large cohort of US men. Circulation 95:59-62.

26. Ye $\mathrm{S}$ et al. (1995) The $4 \mathrm{G} / 5 \mathrm{G}$ genetic polymorphism in the promoter of the plasminogen activator inhibitor-1 (PAl-1) gene is associated with differences in plasma PAI-1 activity but not with risk of myocardial infarction in the ECTIM study. Etude CasTemoins de I'nfarctus du Mycocarde. Thromb. Haemost. 74:837-41.

27. Anonymous. (2002) American Thoracic Society/European Respiratory Society international multidisciplinary consensus classification of the idiopathic interstitial pneumonias. Am. J. Respir. Crit. Care Med. 165:277-304.

28. Flaherty KR et al. (2001) Histopathologic variability in usual and nonspecific interstitial pneumonias. Am. J. Respir. Crit. Care Med. 164:1722-7.

29. Katzenstein AL, Myers JL. (1998) Idiopathic pulmonary fibrosis: clinical relevance of pathologic classification. Am. J. Respir. Crit. Care Med. 157:1301-15.

30. Travis WD, Matsui K, Moss J, Ferrans VJ. (2000) Idiopathic nonspecific interstitia pneumonia: prognostic significance of cellular and fibrosing patterns: survival comparison with usual interstitial pneumonia and desquamative interstitia pneumonia. Am. J. Surg. Pathol. 24:19-33.

31. Daniil ZD et al. (1999) A histologic pattern of nonspecific interstitial pneumonia is associated with a better prognosis than usual interstitial pneumonia in patients with cryptogenic fibrosing alveolitis. Am. J. Respir. Crit. Care Med. 160: 899-905. 